\title{
Notes on the Respiratory Mechanism of Corystes Cassivelaunus.
}

\author{
By \\ Kathleen E. Zimmermann, B.Sc., \\ University College of Wales, Aberystwyth. \\ With Plate V.
}

I. INTRODUCTION.

In his paper in the Journal of the Marine Biological Association for August, 1896, Garstang treated of some structural peculiarities of Corystes cassivelaunus in relation to their biological significance. A brief summary of his observations on the respiratory mechanism may be given as follows: In Corystes cassivelaunus the second antennae are greatly elongated and are fringed by a ventral and a dorsal row of hairs. The opposing rows of hairs interlock, with the resulting formation of a median "antennal tube." The double row of hairs is continued back along the three basal joints of the antennae, which joints are bent at right angles to one another; these hairs, projecting towards the median line, together with a median tuft of hairs springing from the rostrum, form the hairy roof of the proximal part of the antennal tube. The antennal tube opens posteriorly into a median "prostomial chamber," which in turn leads by a wide aperture to the branchial cavity of each side. The prostomial chamber is roofed by the rostrum, the antennal and epistomial sternites, and the prelabial plate. Its floor is imperfect, and is formed by the anterior part of the third maxillipeds behind and in front by a quadrangular sieve of hairs springing from the two basal joints of the second antennal, the anterior pterygostomial processes, and a special anterior process of the fourth joint of the external maxillipeds.

The habit of Corystes is to burrow beneath the sand, where it remains concealed, with only the tip of the antennal tube projecting above the sand surface. A current of water (the respiratory current) is sucked down through the antennal tube, and passes backwards into the prostomial chamber, where it divides into right and left streams, which pass into the right and left branchial chambers. The stream eventually emerges from the branchial chamber along the whole extent of the edge of the branchiostegite. 


\section{SOME STRUCTURAL PECULIARITIES WHICH APPEAR TO HAVE PASSED UNNOTICED BY GARSTANG.}

On that part of the ventral body wall which forms the posterior part of the dorsal wall of the prostomial chamber is a fairly prominent calcified $\mathbf{V}$-shaped ridge, the point of the $\mathbf{V}$ being directed backwards. This ridge is formed by the projecting anterior edge of the epistomial sternite, and is fringed with a row of fairly long hairs, which project quite halfway across the entrance to each branchial chamber.

Some of the mouth appendages of Corystes cassivelaunus-first maxilla and first maxillipede-show a rather curious modification. Comparing these appendages with those corresponding to them in such a type as Cancer (vide Pearson's "Cancer," L.M.B.C. Memoirs, No. xvi), the enlargement of the endopodite is very noticeable. Corystes has the endopodite lobe of each of these appendages (Figs. 4 and 5) specially produced and fringed with hairs of a fairly complex type (Fig. 7).

The mandible of each side is placed with its "apophysis" pointing obliquely backwards, and forming a very prominent ridge projecting towards the ventral side of the animal. Across this ridge lie the specially enlarged endopodite lobes of appendages iv and vi, and over it they are turned up in a dorsal direction, so that their hairy fringes project across the entrance to the branchial chamber proper, meeting the fringe of hairs arising from the $\mathrm{V}$-shaped ridge of the epistomial sternite (cf. Figs. 1, 2 and 3).

Garstang himself notes that the prostomial chamber is but imperfectly floored; it is noticeable that to its central part there is no floor whatever, even a hairy one; and even around its sides the hairs which spring from different parts and converge to the centre neither interlock to any great degree, nor have sufficient individual complexity of structure to constitute anything like a barrier to restrain the in-current of water.

The simple structure of the hairs on the antennae should be noted (Fig. 6) : there is complete absence of any kind of arrangement for filtering the water as it passes from the exterior into the antennal tube, and thence into the prostomial chamber. The habit of Corystes cassivelaunus is to lie buried in sand; the water directly above the surface must necessarily contain some particles of sand or mud, and it is from this by no means clear water that the supply for the respiratory stream is drawn. The complete absence of any arrangement for filtering the water of the incoming current has already been noted, but the sievelike partition formed by the hairs projecting from the specialised endopodites of appendages IV and VI (Fig. 7), together with those of 
the epistomial ridge, appears to constitute a very efficient filter by which particles are rejected at the entrance to the branchial chamber itself. [N.B.-In specimens examined, the hairs of this strainer are muddy.]

The in-current, on reaching the posterior part of the prostomial chamber, must be slightly affected by the presence of the dorsal V-ridge, which, however, seems to be not of sufficient importance to change the course of the whole body of the current. The main mass of the current doubtless sweeps on, is split into right and left streams along the arms of the inverted $\mathbf{V}$ formed by the apophyses of the mandibles, and enters the branchial chambers; meanwhile the small secondary current produced by the influence of the epistomial ridge flows out ventrally through the gap in the hairy ventral wall of the prostomial chamber, sweeping away in its course such particles of mud, etc., as have been prevented by the hairy sieve from entering the branchial chambers with the main current.

\section{SUMMARY.}

Corystes, buries itself in sand for protection, with the tip of the antennal tube, through which enters the respiratory current, projecting. The water which enters the antennal tube cannot be quite clear: there is a hairy filter, which rejects particles of mud, etc., at the entrance to each branchial chamber. The main body of the in-current is split into right and left currents, owing to the position of the apophyses of the mandibles, and these two currents enter respectively the right and left branchial chambers. The epistomial ridge on the roof of the prostomial chamber turns aside some portion of the in-current, which portion passes out ventrally through a gap in the floor of the chamber, carrying out with it foreign particles brought in by the in-current and rejected by the sieves guarding the entrances to the branchial chambers.

\section{EXPLANATION OF PLATE V.}

Fig. 1. Front end of body of Corystes cassivelaunus, ventral view.

a. incompleteness in hairy floor of prostomial chamber.

Fig. 2. View of prostomial chamber from ventral side after removal of most of the mouth appendages.

a. epistomial ridge, fringed with hairs.

b. labrum.

c. entrance to branchial chamber of left side.

d. mandible.

Fig. 3. Diagram longitudinal section a little to one side of the median line.

a. position of antennal tube. e. hairs flooring prostomial chamber.

b. prostomial chamber.

c. hairy strainer.

d. branchial chamber.

$f$. position of maxillae.

g. gap in the hairy floor. 
Journ.Mar. Biol.Assoc. Vol IX

Plate V
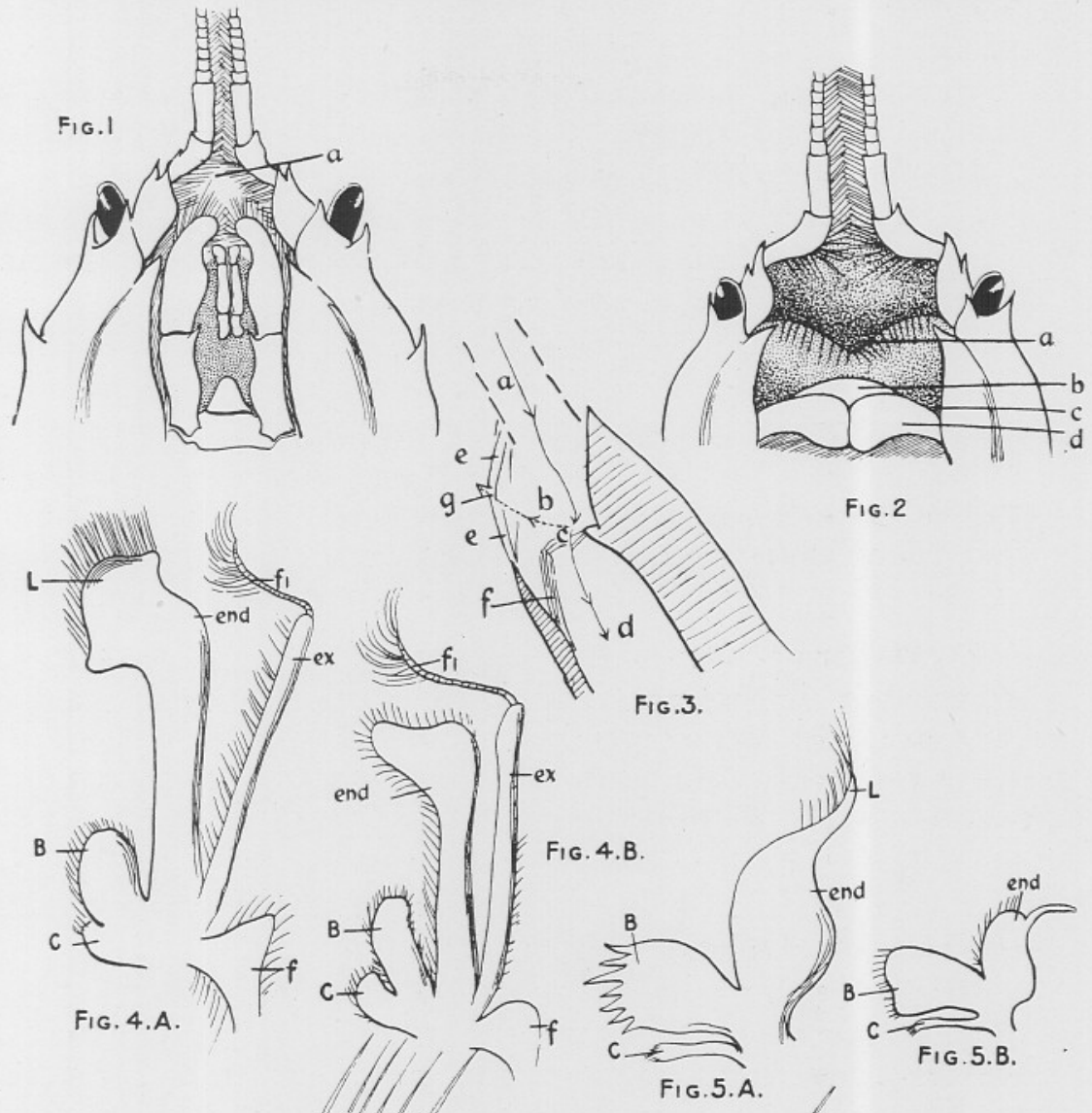

FIG. 2
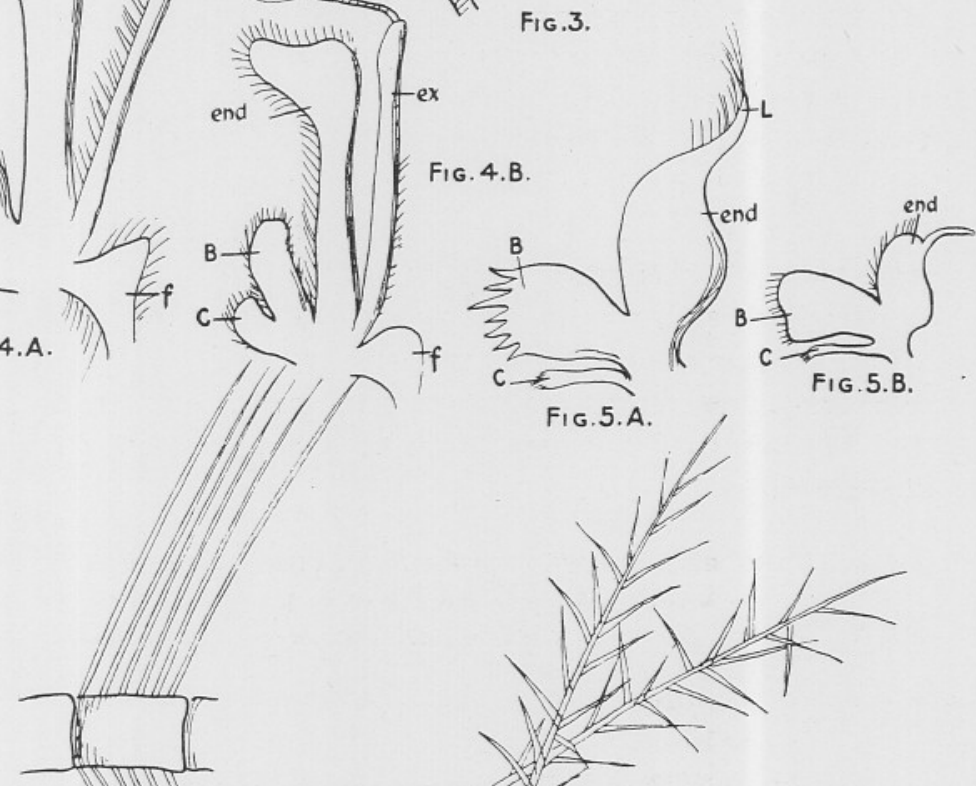

FIG. 6 .

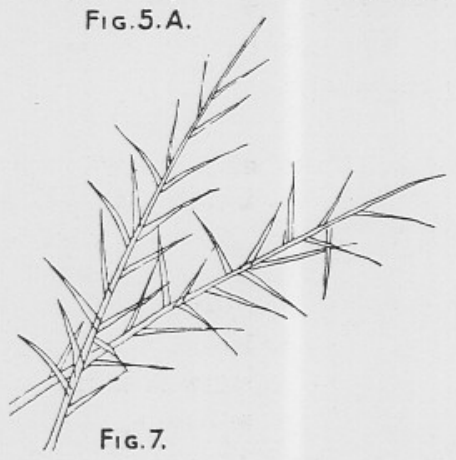


Fig. 4A. First maxillipede of Corystes.
$B$. basipodite.
C. coxopodite.
ex. exopodite.
fl. flagellum.

Fig. 5 A. First maxilla of Corystes.

Lettering as for 4 .

Fig. 6. Part of antenna of Corystes, to show the two rows of simple hairs.

Fig. 7. Straining hairs, such as fringe the endopodites of 4 and 6 in Corystes.
Fig. 4B. First maxillipede of Cancer.

$$
f \text {. flabellum. }
$$

end. endopodite.

$l$. special endopodite lobe, fringed with straining hairs.
Fig. 5B. First maxilla of Cancer. 